\section{(2) OPEN ACCESS}

\title{
Individual and county-level variation in outcomes following non-fatal opioid-involved overdose
}

\author{
Evan Marie Lowder (10 , ${ }^{1}$ Joseph Amlung, ${ }^{2}$ Bradley R Ray ${ }^{3}$
}

${ }^{1}$ Criminology, Law and Society, George Mason University,

Fairfax, Virginia, USA

${ }^{2}$ Regenstrief Institute,

Indianapolis, Indiana, USA

${ }^{3}$ School of Social Work, Wayne

State University, Detroit,

Michigan, USA

Correspondence to

Dr Evan Marie Lowder, Criminology, Law and Society,

George Mason University,

Fairfax, VA 22030, USA;

elowder@gmu.edu

Received 11 July 2019

Revised 26 December 2019

Accepted 31 December 2019

Published Online First

9 January 2020

\section{Check for updates}

(c) Author(s) (or their employer(s)) 2020. Re-use permitted under CC BY-NC. No commercial re-use. See rights and permissions. Published by BMJ.

To cite: Lowder EM

Amlung J, Ray BR. J

Epidemiol Community Health

2020;74:369-376.

\section{ABSTRACT}

Background A lack of large-scale, individually linked data often has impeded efforts to disentangle individuallevel variability in outcomes from area-level variability in studies of many diseases and conditions. This study investigated individual and county-level variability in outcomes following non-fatal overdose in a state-wide cohort of opioid overdose patients.

Methods Participants were 24031 patients treated by emergency medical services or an emergency department for opioid-involved overdose in Indiana between 2014 and 2017. Outcomes included repeat non-fatal overdose, fatal overdose and death. County-level predictors included sociodemographic, socioeconomic and treatment availability indicators. Individual-level predictors included age, race, sex and repeat non-fatal opioid-involved overdose. Multilevel models examined outcomes following non-fatal overdose as a function of patient and county characteristics.

Results $10.9 \%(n=2612)$ of patients had a repeat non-fatal overdose, $2.4 \%$ ( $n=580)$ died of drug overdose and $9.2 \%(n=2217)$ died overall. Patients with a repeat overdose were over three times more likely to die of drug-related causes $(\mathrm{OR}=3.68,99.9 \% \mathrm{Cl} 2.62$ to 5.17 , $p<0.001)$. County-level effects were limited primarily to treatment availability indicators. Higher rates of buprenorphine treatment providers were associated with lower rates of mortality ( $O R=0.82,95 \% \mathrm{Cl} 0.68$ to $0.97, p=0.024)$, but the opposite trend was found for naltrexone treatment providers $(\mathrm{OR}=1.20,95 \% \mathrm{Cl}$ 1.03 to $1.39, p=0.021$ ). Cross-level interactions showed higher rates of Black deaths relative to White deaths in counties with high rates of naltrexone providers ( $\mathrm{OR}=1.73,95 \% \mathrm{Cl} 1.09$ to $2.73, \mathrm{p}=0.019$ ).

Conclusion Although patient-level differences account for most variability in opioid-related outcomes, treatment availability may contribute to county-level differences, necessitating multifaceted approaches for the treatment and prevention of opioid abuse.

\section{INTRODUCTION}

The USA is experiencing an overdose epidemic, driven by rising opioid-involved deaths. ${ }^{12}$ Originally attributed to overprescribing, ${ }^{3}$ the growing lethality of this epidemic is now attributed to illicit opioids, mainly fentanyl, with rapidly rising deaths among racial and ethnic minorities. ${ }^{245}$ The widespread nature of this epidemic has prompted investigation into sources of variability in overdose rates, especially geographic variation. Beyond state-level variation, ${ }^{67}$ regional and county-level differences in overdose rates have been documented. ${ }^{8-12}$ Higher rates of overdose deaths, especially opioid-involved deaths, have been linked to locales with greater proportions of residents who are White, female and aged $35-55,{ }^{11} 1314$ as well as higher rates of economic and social disadvantage. ${ }^{1014}$

Despite growing research on geographic determinants of overdose outcomes, several limitations should be noted. Primarily, reliance on geographic-level data without accounting for individual-level variability has been criticised as an ecological fallacy, ${ }^{15}$ whereby inferences about individual behaviour are deduced incorrectly from local trends. Relatedly, the lack of large-scale, individually linked data has limited investigation into whether geographic variation in outcomes reflects individual-level differences. Yet, there is emerging evidence of racial disparities in fatal overdose outcomes. ${ }^{2}{ }^{4}$ Disparities in access to education, housing, healthcare, employment and financial resources manifest from structural inequalities, and researchers have used community-level indicators of these characteristics to examine disparities in health outcomes, ${ }^{16}$ suggesting these indicators may inform individual-level disparities in drug overdose trends. Finally, limited availability of patient-level data has restricted investigation into non-fatal overdose outcomes. However, research on the course of opioid abuse shows fewer than $30 \%$ of users achieve abstinence over time. ${ }^{17}$ And, although opioid users are at heightened risk of death relative to the general population, ${ }^{17}$ only one-fifth die of drug-related causes. ${ }^{18}$ These trends have prompted investigation into the epidemiology of non-fatal overdose to inform intervention strategies prior to fatal outcomes. ${ }^{1920}$

Government-led data linkage initiatives may increase the accessibility of individually linked data for the research community and the public visibility of individual trends in opioid outcomes. However, we are aware of only a few efforts to construct large and individually linked data sets to address this epidemic. ${ }^{19-21}$ British Columbia, for example, has established a province-level overdose cohort of fatal and non-fatal overdose patients to track antecedents of overdose events. ${ }^{20}$ The present study leveraged data from the Indiana Management Performance Hub (MPH), a state agency tasked with coordinating data linkage to inform policy, to investigate individual and county-level predictors of overdose-related outcomes in a state-wide cohort of non-fatal overdose patients from 2014 through $2017(n=24031)$. In addition to examining countylevel predictors of opioid-related outcomes drawn from past studies, ${ }^{8101422-25}$ we examine treatmentrelated predictors hypothesised to explain countylevel variability in opioid outcomes. ${ }^{26}$ Given 
growing evidence of racial disparities in overdose outcomes, our secondary aim was to examine the extent to which county-level trends in opioid-related outcomes were moderated by individual race.

\section{METHODS}

\section{Sample}

We analysed records from a state-wide sample of 24031 patients in Indiana aged 15 and older who had an emergency encounter for a suspected opioid overdose and survived. Patients were mainly White $(n=22399,93.2 \%)$ versus Black $(n=1632,6.8 \%)$ and two-thirds male $(\mathrm{n}=14151,58.9 \%)$. Patients were primarily aged 15-24 ( $\mathrm{n}=3836,16.0 \%), 25-34(\mathrm{n}=7244,30.1 \%), 35-44$ $(n=4303,17.9 \%)$ and $45-54(n=3264,13.6 \%)$. Fewer participants were aged 55-64 $(\mathrm{n}=2581,10.7 \%), 65-74 \quad(\mathrm{n}=1368$, $5.7 \%), 75-84(\mathrm{n}=867,3.6 \%)$ or 85 plus $(\mathrm{n}=568,2.4 \%)$.

\section{Procedure}

From MPH we received deidentified, individual-level population data on all emergency medicine encounters in Indiana between 1 January 2014 and 31 December 2017. MPH partners with other agencies, including public health, behavioural health and public safety, to integrate administrative data sources and inform data-driven policymaking. MPH records were collated from three separate data sources. Emergency medical services (EMS) records were sourced from the Indiana Department of Homeland Security (IDHS). Per Section 836 of the Indiana Administrative Code 1-1-5, EMS providers are required to submit records from the National Emergency Medical Service Information System to IDHS. Emergency department (ED) records were sourced from the Indiana State Department of Health (ISDH). EDs are required to report syndromic surveillance data to ISDH, per Section 410 of the Indiana Administrative Code 1-2.4. Finally, vital records were sourced from ISDH for all deaths in Indiana, per Title 16 of the Indiana Code Article 37 Chapter 1-3.1. Individual demographics were collated from event records. Conflicting records were reconciled using the most recent non-null value. If multiple events happened on the same day, preference was given in the following order: death record, arrest record, ED visit, prescription dispensation and EMS run. Suspected opioid-involved overdose encounters with EMS were indicated by naloxone administration. ED visits involving an opioid overdose were determined from patient chief complaints and discharge diagnosis codes (International Classification of Diseases-Tenth Revision-Clinical Modification (ICD-10-CM), ICD-9-CM or Systematized Nomenclature of Medicine-Clinical Terms). The Indiana University Institutional Review Board determined this study to be exempt.

We assigned patients to Indiana counties via zip codes based on most probable county membership. Because we modelled multiple events that may have generated multiple zip codes for patients, we used residential location instead of place of injury to assign patients to counties. Of 683 zip codes, 676 were completely or primarily (ie, $>50 \%$ of residents) located in one county. Only $7(1.2 \%)$ zip codes were assigned to counties where $<50 \%$ of zip code residents resided. Overall, the data included a census of 14064623 emergency medical events of which 35466 involved a suspected opioid-related overdose. Duplicate EMS and ED events $(n=2289)$ where patients received services on the same day were consolidated into one record. In total, 29102 unique patients had one or more overdoses over the study period. Consistent with study aims, we removed 1187 cases where patients were identified as a race other than Black or White, 164 cases where the patient was under age 15 and 1750 cases where the zip code was outside of Indiana or was unknown. Of 26001 remaining patients, 814 had missing demographic information. Finally, 1152 patients died within 1 day of the first overdose event, and an additional four were excluded for other reasons. The final sample included 24031 patients who had a suspected opioid-involved overdose and survived.

\section{Variables}

Individual-level predictors included race (Black, White), sex (female, male), age and time at risk (days). Age categories were dummy coded per the Centers for Disease Control and Prevention age groups for mortality data (ie, 25-34, 35-44, 45-54, $55-64,65-74,75-84,85$ plus) with $15-24$ as the reference category. Time at risk was operationalised as the number of days from the initial non-fatal overdose event for each patient to the end of the study period (31 December 2017) or the date of death if the patient died during the study period. Time at risk was included as a conditional effect in non-survival models and the outcome of interest in survival models. Repeat non-fatal opioidinvolved overdose (yes, no) was included in models of any death or any drug-related death.

County-level predictors were selected if they were included in two or more investigations of geographic-level variability in drug overdose-related outcomes, primarily mortality. 8101422252728 Median family income was highly collinear with racial composition (ie, percentage Black), $r(90)=0.89, p<0.001$, and excluded as a covariate. We included gender (ie, proportion male) due to its inclusion in other investigations of related outcomes. ${ }^{24} 29$ Finally, we examined three treatment-related predictors hypothesised to relate to geographic variability in opioid outcomes ${ }^{26}$ : rate of halfway house providers, rate of buprenorphine providers and rate of naltrexone providers. See table 1 for description of data sources. When possible, county-level variables were coded based on 2014 estimates, representing the start of the study period. With the exception of rate of opioid prescription pills dispensed (rate per 100000 ), rates were calculated as the rate per 10000 residents based on 20145 -year population estimates. ${ }^{30}$

Outcome variables were dichotomous (yes, no) and included any repeat non-fatal opioid-involved overdose, any death and any drug-related death occurring during the study period. Drugrelated deaths were coded based on ICD-10 codes from vital records indicating an underlying cause of death (X41-42, X44, $\mathrm{X} 47, \mathrm{X} 60-62, \mathrm{X} 64, \mathrm{X} 67, \mathrm{Y} 12, \mathrm{Y} 14)$.

\section{Analytical approach}

We conducted descriptive statistics on study outcomes overall and by race. Additionally, we computed crude mortality rate (CMR) and standardised mortality rate (SMR) overall and by repeat non-fatal overdose during the study period. SMRs were calculated by estimating the probability of death for each patient based on the length of follow-up period and 2014 state-wide mortality estimates by age, race and sex. ${ }^{31}$ Resulting probabilities were summed to compute a ratio of observed deaths to expected deaths.

Multilevel models examined outcomes following non-fatal overdose. First, we conducted mixed models using PROC GLIMMIX in SAS V.9.4 software. Unconditional models were conducted to establish significant variability at each level of analysis. $^{32}$ Continuous level 2 variables were standardised $(\mathrm{M}=0$, $\mathrm{SD}=1$ ) to allow for within-model comparison of level 2 effects. We initially conducted multivariable main effects models with level 1 and level 2 predictors as conditional effects. Subsequently, 
Table 1 Measurement and data source for county-level variables

\begin{tabular}{llll}
\hline Variable & Measurement & Source & \\
\hline Rural/urban & Binary & US Department of Agriculture, Office of Rural Health Policy & 2010 \\
\hline Percentage Black & Continuous & US Census American Community Survey & 2014 \\
\hline Percentage Hispanic & Continuous & US Census American Community Survey & 2014 \\
\hline Percentage over 65 & Continuous & US Census American Community Survey & 2014 \\
\hline Percentage male & Continuous & US Census American Community Survey & 2014 \\
\hline Poverty rate & Continuous & US Census American Community Survey & 2014 \\
\hline Percentage no high school diploma & Continuous & US Census American Community Survey & 2014 \\
\hline Unemployment rate & Continuous & US Census American Community Survey & 2014 \\
\hline Active medical doctor rate & Continuous & Health Resources and Services Administration & 2014 \\
\hline Opioid pills dispensed rate & Continuous & Epidemiology Resource Center, Indiana State Department of Health & 2014 \\
\hline Halfway house provider rate & Continuous & National Directory of Drug and Alcohol Abuse Treatment Programs & 2014 \\
\hline Buprenorphine provider rate & Continuous & National Directory of Drug and Alcohol Abuse Treatment Programs & 2014 \\
\hline Naltrexone provider rate & Continuous & National Directory of Drug and Alcohol Abuse Treatment Programs & 2014 \\
\hline
\end{tabular}

we tested cross-level interactions for level 2 indicators of treatment availability (ie, naltrexone treatment provider, buprenorphine treatment provider and halfway house provider rates) with race while controlling for level 1 and level 2 predictors. All patients were included in models predicting likelihood of a drug-related death or any death, and all models controlled for time at risk.

Second, to account for the variable follow-up period length and right-censored nature of study data, we conducted multilevel survival models in Stata V.14 using the mestreg command and specifying a Weibull distribution. For these analyses, we examined outcomes 1 year following the initial non-fatal overdose in a modified sample of 16417 patients who had 1 year of follow-up data available. County-level differences in outcomes were adjusted by including a random effect for county. Level 1 predictors were included as conditional effects.

Due to the large sample size at level 1 , and the potential for type 1 error, we used a $\mathrm{p}<0.001$ criterion for interpreting level 1 effects. For level 2 effects and any effect involving level 2 variable, we employed a $\mathrm{p}<0.05$ criterion. Where relevant, we report estimated marginal rates and associated $95 \%$ and $99.9 \%$ CIs.

\section{RESULTS}

\section{Descriptive}

Patients were at risk for an average of 573.18 days $(S D=387.76$, range: $0-1460)$. Survival outcomes overall and by race are presented in table 2 . Overall, $10.9 \%$ of patients $(n=2612)$ had a repeat non-fatal opioid overdose and 10.3\% $(n=270)$ of those died over the study period. Most patients with a repeat non-fatal overdose experienced one event $(n=1894,72.5 \%)$. Overall, $9.2 \%$ of patients $(n=2217)$ died, primarily of non-drug-related causes $(n=1637,73.8 \%)$. CMRs were 5.87 (95\% CI 5.63 to
6.11) per 100 person-years for patients overall, 5.76 (95\% CI 5.50 to 6.02 ) for patients without a repeat non-fatal overdose and 6.66 (95\% CI 5.94 to 7.38$)$ for patients with a repeat nonfatal overdose. SMRs were 7.26 (95\% CI 6.96 to 7.57) for patients overall, 6.59 (95\% CI 6.29 to 6.89) for patients without a repeat non-fatal overdose and 17.57 (95\% CI 15.73 to 19.58$)$ for patients with a repeat non-fatal overdose.

\section{Multilevel models}

Unconditional models showed significant variability at both levels of analysis for all outcomes, all $p<0.001$. County-level intraclass correlation coefficient estimates suggested countylevel differences explained $7.5 \%$ of variability in repeat non-fatal opioid-involved overdose, $11.4 \%$ of variability in likelihood of any death and $9.6 \%$ in likelihood of drug-involved death. Main effects models are presented in table 3. Significant individuallevel predictors of any repeat non-fatal opioid overdose included sex $(\mathrm{p}<0.001)$, with men at higher risk $(9.4 \%, 99.9 \%$ CI $6.6 \%$ to $13.2 \%)$ relative to women $(8.2 \%, 99.9 \%$ CI $5.7 \%$ to $11.7 \%)$, and age. Older age groups showed lower likelihood of repeat non-fatal overdose relative to 15-24 year-olds. At the county level, higher rates of halfway house providers were associated with higher rates of repeat non-fatal overdose.

As shown in table 3, for drug-related death, significant effects included older age (65-84) and repeat non-fatal overdose during the study period. Patients with a repeat non-fatal overdose were three times more likely to die of fatal overdose $(3.2 \%, 99.9 \% \mathrm{CI}$ $2.0 \%$ to $5.1 \%$ ) relative to patients without a repeat non-fatal overdose $(0.9 \%, 99.9 \%$ CI $0.6 \%$ to $1.4 \%)$. At the county level, higher poverty rates were associated with lower rates of fatal overdose. Rates of halfway house and naltrexone treatment providers were positively associated fatal overdose.

Table 2 Descriptive statistics and bivariable comparison of study period survival outcomes by race

\begin{tabular}{|c|c|c|c|c|c|c|c|c|}
\hline \multirow[b]{3}{*}{ Group } & \multirow{3}{*}{$\begin{array}{l}\begin{array}{l}\text { Total } \\
\mathrm{n}=24031\end{array} \\
\mathrm{n}(\%)\end{array}$} & \multicolumn{2}{|l|}{$\begin{array}{l}\text { Survived } \\
\mathrm{n}=21814\end{array}$} & \multicolumn{2}{|l|}{$\begin{array}{l}\text { Died } \\
\mathrm{n}=2217\end{array}$} & \multirow[b]{2}{*}{ Comparison } & \multirow[b]{3}{*}{$P$ value } & \multirow[b]{3}{*}{$\Phi$} \\
\hline & & No repeat non-fatal OD & Repeat non-fatal OD & Drug related & Non-drug related & & & \\
\hline & & n (\%) & n (\%) & n (\%) & n (\%) & $\chi^{2}(\mathrm{df})$ & & \\
\hline Black & $1632(6.8)$ & $1369(83.9)$ & $127(7.8)$ & $28(1.7)$ & $108(6.6)$ & $12.32(3)$ & 0.006 & 0.02 \\
\hline White & $22399(93.2)$ & $18103(80.8)$ & $2215(9.9)$ & $552(2.5)$ & $1529(6.8)$ & & & \\
\hline
\end{tabular}

OD, overdose. 


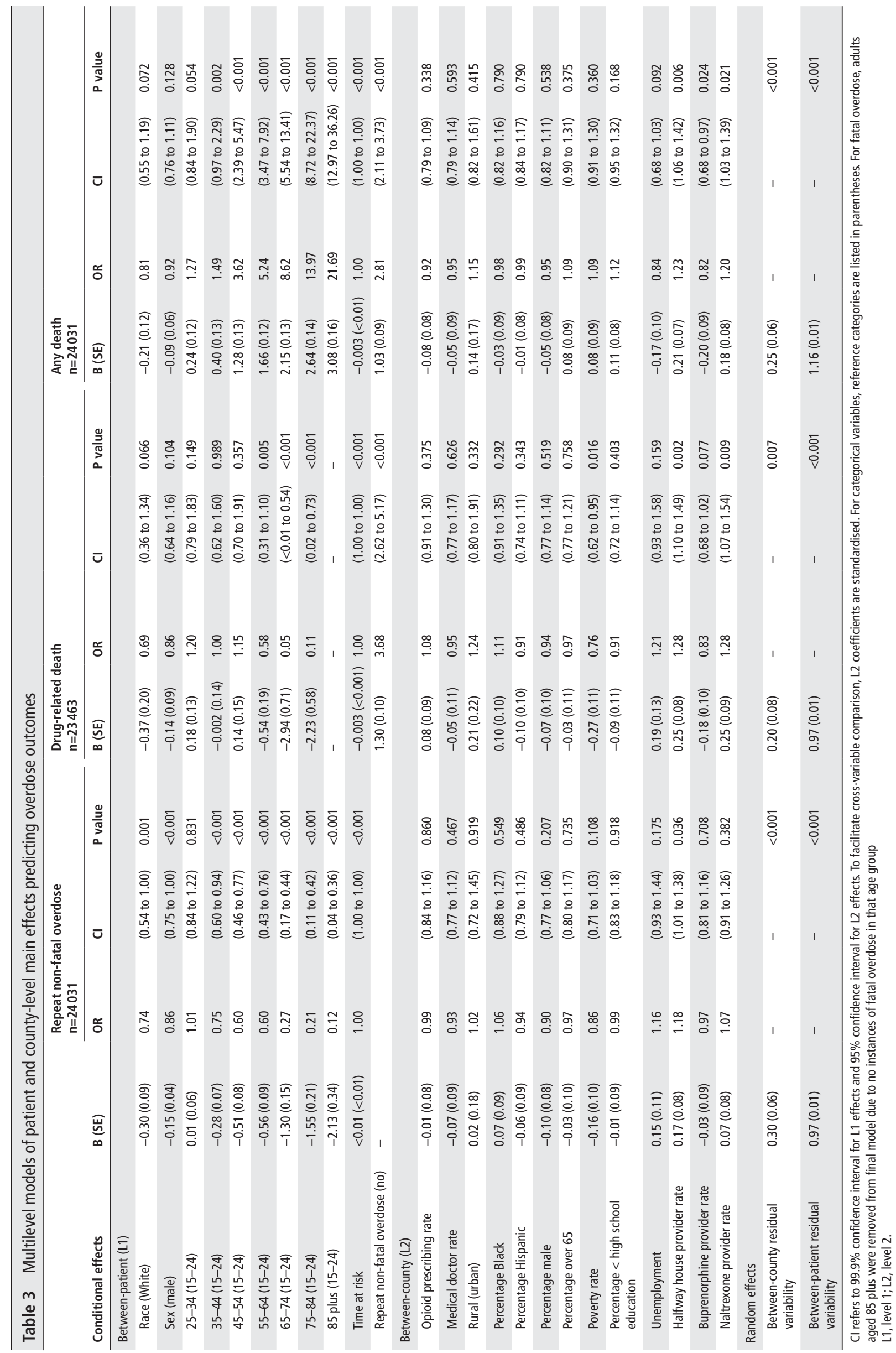




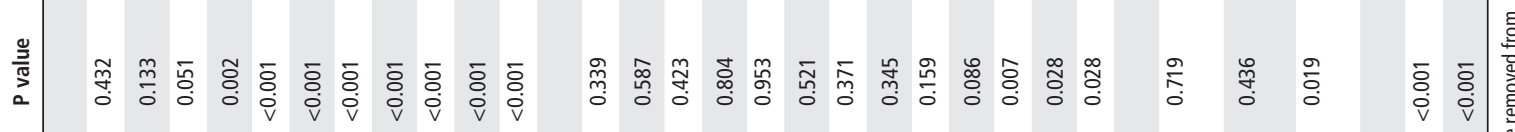

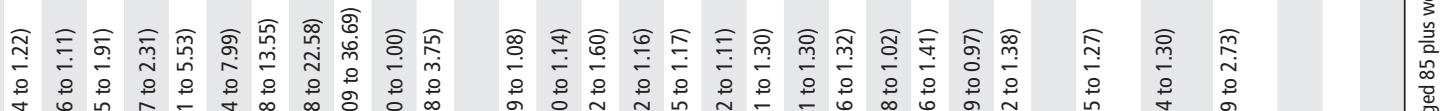

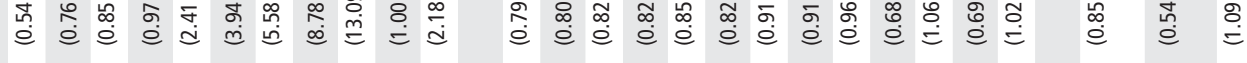

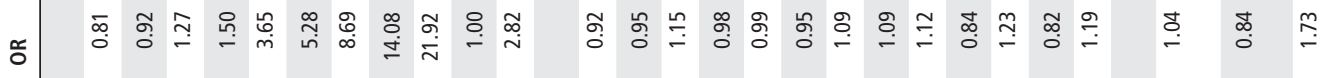

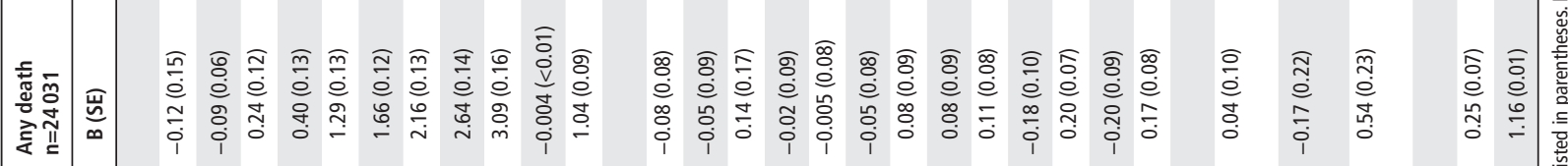

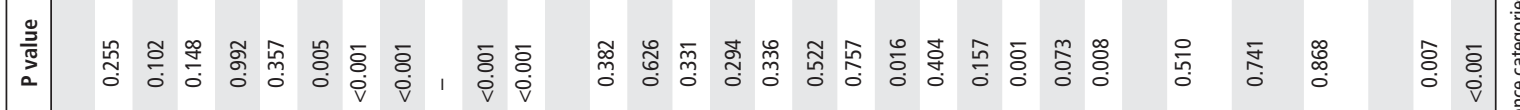

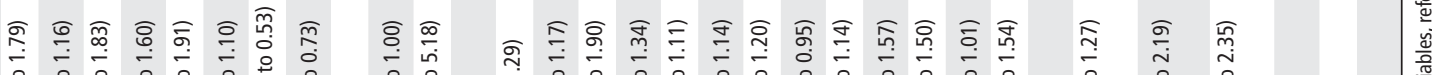
$\bar{\tau}$

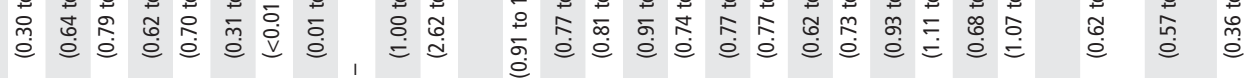

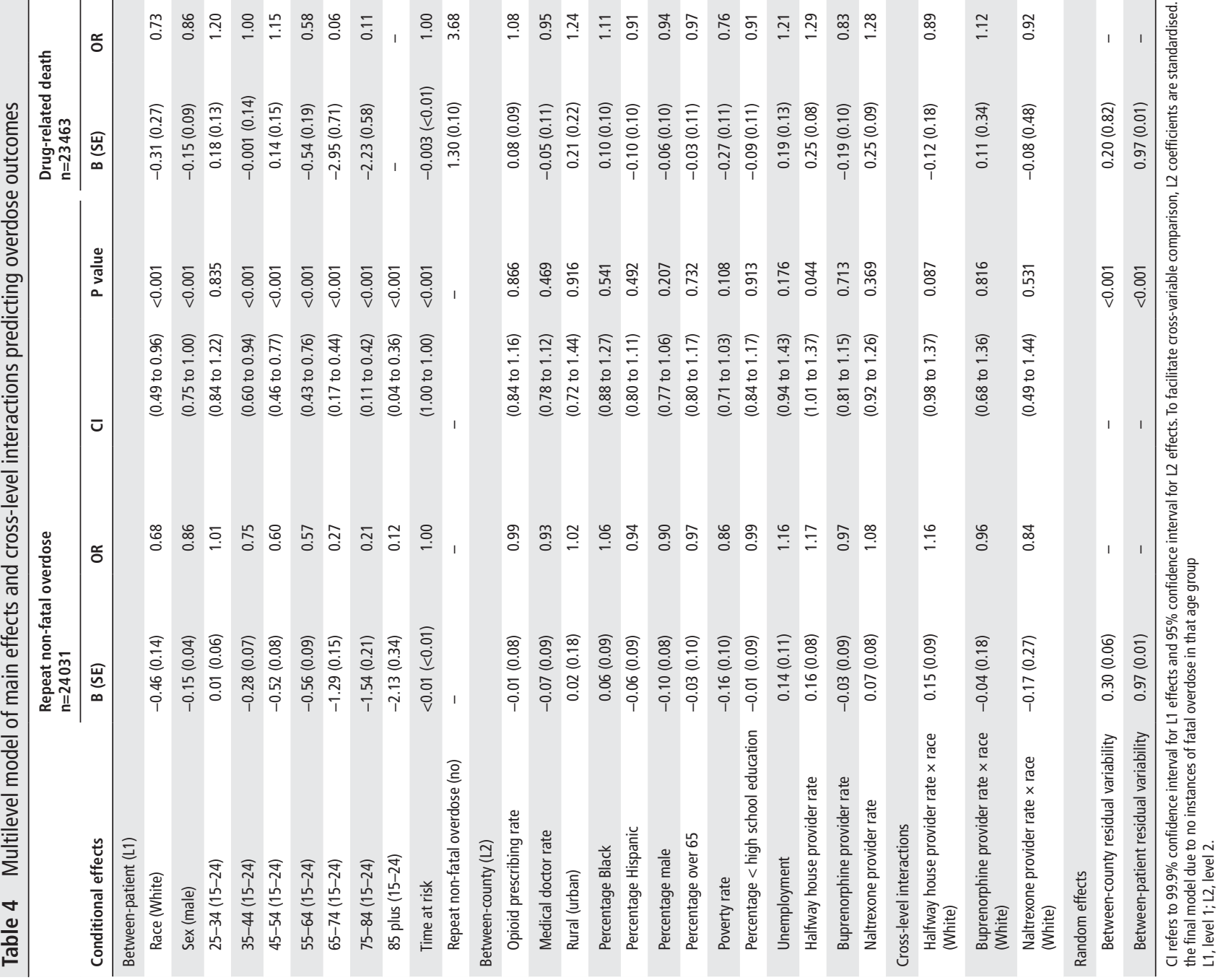


Table 5 Multilevel survival models of overdose outcomes

\begin{tabular}{|c|c|c|c|c|c|c|c|c|c|}
\hline \multirow[b]{2}{*}{ Conditional effects } & \multicolumn{3}{|c|}{$\begin{array}{l}\text { Repeat non-fatal overdose } \\
n=16417\end{array}$} & \multicolumn{3}{|c|}{$\begin{array}{l}\text { Drug-related death } \\
\mathrm{n}=15998\end{array}$} & \multicolumn{3}{|l|}{$\begin{array}{l}\text { Any death } \\
n=16417\end{array}$} \\
\hline & HR (SE) & $\mathrm{Cl}$ & $P$ value & HR (SE) & $\mathrm{Cl}$ & $P$ value & HR (SE) & $\mathrm{Cl}$ & $P$ value \\
\hline \multicolumn{10}{|l|}{ Between-patient (L1) } \\
\hline Race (White) & $0.76(0.09)$ & (0.51 to 1.14 ) & 0.093 & $0.60(0.18)$ & (0.22 to 1.60$)$ & 0.085 & $0.88(0.11)$ & (0.58 to 1.34$)$ & 0.317 \\
\hline Sex (male) & $0.88(0.05)$ & (0.73 to 1.06$)$ & 0.021 & $0.84(0.10)$ & (0.56 to 1.25$)$ & 0.151 & $0.82(0.05)$ & (0.68 to 0.99 ) & $<0.001$ \\
\hline $25-34(15-24)$ & $1.02(0.07)$ & (0.80 to 1.29$)$ & 0.801 & $1.75(0.32)$ & (0.96 to 3.17 ) & 0.002 & $1.60(0.25)$ & (0.96 to 2.65 ) & 0.002 \\
\hline $35-44(15-24)$ & $0.75(0.06)$ & (0.56 to 0.99 ) & 0.001 & $1.54(0.31)$ & (0.79 to 3.01 ) & 0.035 & $2.20(0.35)$ & (1.30 to 3.72 ) & $<0.001$ \\
\hline $45-54(15-24)$ & $0.70(0.07)$ & (0.51 to 0.96$)$ & $<0.001$ & $1.73(0.37)$ & (0.86 to 3.47 ) & 0.010 & $3.92(0.60)$ & (2.38 to 6.48 ) & $<0.001$ \\
\hline $55-64(15-24)$ & $0.73(0.08)$ & (0.52 to 1.04$)$ & 0.003 & $1.24(0.41)$ & (0.54 to 2.82$)$ & 0.389 & $6.57(0.97)$ & (4.03 to 10.71 ) & $<0.001$ \\
\hline $65-74(15-24)$ & $0.26(0.05)$ & (0.13 to 0.52$)$ & $<0.001$ & $0.10(0.10)$ & (<0.01 to 2.76$)$ & 0.022 & $11.00(1.67)$ & (6.67 to 18.14 ) & $<0.001$ \\
\hline $75-84(15-24)$ & $0.24(0.07)$ & (0.09 to 0.60$)$ & $<0.001$ & $0.33(0.24)$ & (0.03 to 3.65$)$ & 0.132 & $16.30(2.52)$ & (9.79 to 27.13 ) & $<0.001$ \\
\hline 85 plus (15-24) & $0.09(0.05)$ & (0.01 to 0.58 ) & $<0.001$ & - & - & - & $27.39(4.28)$ & (16.38 to 45.81 ) & $<0.001$ \\
\hline $\begin{array}{l}\text { Repeat non-fatal } \\
\text { overdose (no) }\end{array}$ & - & - & - & $3.02(0.40)$ & (1.94 to 4.69 ) & $<0.001$ & $1.69(0.16)$ & (1.24 to 2.30$)$ & $<0.001$ \\
\hline \multicolumn{10}{|l|}{ Random effects } \\
\hline $\begin{array}{l}\text { Between-county } \\
\text { variability }\end{array}$ & $0.23(0.05)$ & ( 0.10 to 0.51 ) & & & & & & & \\
\hline
\end{tabular}

$\mathrm{HR}=$ hazard ratio produced by multilevel survival models. Cl refers to $99.9 \%$ confidence interval for $\mathrm{L} 1$ effects. For categorical variables, reference categories are listed in parentheses. For fatal overdose, adults aged 85 plus were removed from the final model due to no instances of fatal overdose in that age group.

L1, level 1.

Significant individual-level predictors of any death were limited primarily to age variables (see table 3 ). However, patients with a repeat non-fatal overdose were at greater likelihood of death overall $(8.6 \%, 99.9 \%$ CI $5.8 \%$ to $12.8 \%)$ compared with patients without a repeat overdose $(3.3 \%, 99.9 \%$ CI $2.2 \%$ to $4.7 \%), p<0.001$. At the county level, higher rates of halfway house and naltrexone treatment providers were associated with

\section{What is already known on this subject}

- A growing number of studies have shown evidence of geographic variability in opioid-related outcomes, including mortality.

- Community characteristics such as relative social and economic disadvantage have been associated with higher rates of opioid-related mortality across jurisdictions.

- Due to the limited availability of large-scale, patient-level data on opioid outcomes, few studies have examined whether county-level associations persist after accounting for patient-level variability in outcomes.

\section{What this study adds}

- Patient-level differences accounted for the vast majority of variability in opioid outcomes, with a repeat non-fatal overdose serving as the strongest risk factor for fatal overdose.

- After accounting for patient-level differences, few community-level socioeconomic or sociodemographic characteristics drawn from prior research were associated with opioid-related outcomes. Instead, availability of community treatment providers emerged as the most consistent predictor of community-level differences in opioid outcomes.

- Community-level strategies to address the opioid epidemic should focus on treatment access in high-risk communities. higher rates of death while higher rates of buprenorphine treatment providers were negatively associated with death.

\section{Cross-level interactions}

Table 4 presents multivariable models with cross-level interactions of county-level treatment availability by race. Controlling for other conditional effects, there were no significant crosslevel interactions in the prediction of repeat non-fatal overdose or drug-related death (all $\mathrm{p}>0.087$ ). However, for any death, the rate of naltrexone treatment providers showed a significant interaction with race $(p=0.019)$. Decomposition of this interaction at $+1 /-1$ SDs suggested Black patients had higher rates of death $(6.4 \%, 95 \%$ CI $3.6 \%$ to $11.1 \%)$ in counties with higherthan-average naltrexone treatment provider rates versus lowerthan-average naltrexone treatment provider rates $(1.7 \%, 95 \% \mathrm{CI}$ $0.9 \%$ to $2.7 \%$ ). This trend was less apparent for White patients, who had similar rates of any death in counties with higher-thanaverage $(4.4 \%, 95 \% \mathrm{CI} 3.4 \%$ to $5.7 \%)$ and lower-than-average $(3.2 \%, 95 \%$ CI $2.3 \%$ to $4.7 \%)$ naltrexone treatment provider rates.

Multilevel survival models

Results of multilevel survival analyses are shown in table 5. As shown, after adjusting for county-level differences in outcomes, older age groups had a lower hazard of repeat non-fatal overdose but higher hazard of any death relative to patients aged 15-24 (all $\mathrm{p}<0.001)$. Women had a lower hazard of any death relative to men $(\mathrm{HR}=0.82,95 \% \mathrm{CI} 0.68$ to $0.99, \mathrm{p}<0.001)$. Having a repeat non-fatal overdose increased the hazard of a drug-related death by 3.02 (95\% CI 1.94 to $4.69, \mathrm{p}<0.001)$ and the hazard of any death by $1.69(95 \%$ CI 1.24 to $2.30, \mathrm{p}<0.001)$ relative to no repeat non-fatal overdose.

\section{DISCUSSION}

We used a state-wide, individually linked data set to examine individual and county-level variability in fatal and non-fatal overdose outcomes over a 4-year period. Overall, our findings showed that few sociodemographic and socioeconomic countylevel measures drawn from prior research were significant 
predictors of county-level variability in outcomes. Additionally, most variability was explained by individual-level differences. A small, but clinically significant, portion of non-fatal overdose patients ( 1 in 10) were at risk for repeat non-fatal overdose over a multiyear period; roughly 1 in 50 patients were at risk for fatal overdose. More broadly, patients with repeat nonfatal overdoses are at heightened risk of drug-related death and are unlikely to receive evidence-based treatment for opioid use disorder following non-fatal overdose, ${ }^{33}$ highlighting the critical role of emergency medical settings in the identification and treatment engagement of high-risk patients. ${ }^{34} 35$

County-level effects primarily reflected county-wide indicators of overdose prevalence and treatment availability. For example, counties with higher-than-average rates of naltrexone treatment providers had higher rates of fatal overdose and mortality. Although naltrexone use has grown more slowly than other medication-assisted therapies for substance use disorder, it remains popular in Indiana: 30\% of counties had a naltrexone provider in 2014 (vs 20\% with a buprenorphine provider). High rates of naltrexone use-especially Vivitrol, the extended-release injectable-have been attributed in part to aggressive marketing by pharmaceutical lobbyists. ${ }^{36}$ Evidence from clinical trials suggests it may be less effective than buprenorphine or methadone due to the extensive detoxification period required prior to initiation that serves as a barrier to treatment engagement. ${ }^{37}$ Our findings provide limited support for a beneficial effect of naltrexone availability on county-level mortality.

Further analysis showed that the effect of naltrexone treatment availability on mortality varied by race. Specifically, counties with greater availability of naltrexone providers had higher rates of Black deaths, suggesting that Black patients experienced barriers to treatment access or lack of alternative treatment options. Although there has been limited investigation of the use of naltrexone for opioid use disorder among Black patients, prior studies have found naltrexone is less efficacious for alcohol use in Black versus White patients. ${ }^{38} 39$ Relative to other medicationassisted therapies for opioid use disorder, prior studies have documented more resistance to the induction of extendedrelease naltrexone in community treatment settings, though not specifically among Black patients. ${ }^{37}$ However, barriers to naltrexone treatment initiation could explain disparate findings between naltrexone and buprenorphine, where findings were consistent with evidence on the effectiveness of buprenorphine on overdose outcomes, including mortality. ${ }^{40}$

Study limitations may guide future research on county-level distribution of opioid-related outcomes. Primarily, our investigation was retrospective and limited to available administrative records. Although we examined a multiyear period, this investigation was cross-sectional, not longitudinal. There may have been policy changes occurring in Indiana during this time that affected county-level practices. Efforts to integrate public data systems in response to this epidemic likely will increase the feasibility of conducting prospective, longitudinal and realtime data analysis to guide local policymaking. Additionally, we were unable to make causal inferences about the effects of county-level predictors on county-level variability in outcomes. Future longitudinal investigations may benefit from the inclusion of time-varying predictors to inform how opioid-related outcomes change as county characteristics vary from year to year. Finally, our investigation examined county-level, statistical variation in opioid-related outcomes. We did not conduct geospatial analysis nor adjust for spatial autocorrelation in our analyses. A growing number of studies have used these methodologies to model geographic variation in opioid outcomes, and further work in this area will be necessary as this epidemic evolves.

Despite limitations, our investigation is one of the first to examine individual and community-level predictors of opioidrelated outcomes using patient-level data. Our findings overall suggest limited utility of sociodemographic and socioeconomic indicators in explaining between-county differences in opioid outcomes. Rather, our findings underscore the importance of individual characteristics in predicting opioid-related outcomes and point to treatment availability as a potential contributor to county-level differences in outcomes following non-fatal overdose.

Contributors EML and BRR conceived the study. EML and JA cleaned and coded the study data. EML conducted the data analysis, with intellectual contribution from BRR. EML and BRR codrafted the manuscript. All authors approved the final manuscript. EML takes responsibility for its final content.

Funding This work was funded through Indiana's State Opioid Response Grant from the Substance Abuse and Mental Health Services Administration (TI081689-01)

Disclaimer The contents are solely the responsibility of the authors and do not necessarily represent the official views of the State of Indiana or the Substance Abuse and Mental Health Services Administration. The funding source played no role in the design, conduct or reporting of this investigation.

Competing interests EML and BRR contracted with Indiana's Management Performance Hub to complete this work as part of the Indiana's State Opioid Response Grant from the Substance Abuse and Mental Health Services Administration.

\section{Patient consent for publication Not required.}

Provenance and peer review Not commissioned; externally peer reviewed.

Data availability statement Data may be obtained from a third party and are not publicly available. Deidentified, patient-level data were provided to the researchers by the Indiana Management Performance Hub (MPH). MPH has an established process for external data requests. More information can be found at the following link: https://www.in.gov/mph/935.htm

Open access This is an open access article distributed in accordance with the Creative Commons Attribution Non Commercial (CC BY-NC 4.0) license, which permits others to distribute, remix, adapt, build upon this work non-commercially, and license their derivative works on different terms, provided the original work is properly cited, appropriate credit is given, any changes made indicated, and the use is non-commercial. See: http://creativecommons.org/licenses/by-nc/4.0/.

\section{ORCID iD}

Evan Marie Lowder http://orcid.org/0000-0002-5855-2479

\section{REFERENCES}

1 Hedegaard H, Warner M, Miniño AM. Drug overdose deaths in the United States, 1999-2016. Hyattsville, MD: National Center for Health Statistics, 2017. https://www. cdc.gov/nchs/data/databriefs/db294.pdf

2 Seth P, Scholl L, Rudd RA, et al. Overdose deaths involving opioids, cocaine, and psychostimulants — United States, 2015-2016. MMWR Morb Mortal Wkly Rep 2018;67:349-58

3 Manchikanti L, Helm S, Fellows B, et al. Opioid epidemic in the United States. Pain Physician 2012;15:ES9-38.

4 Alexander MJ, Kiang MV, Barbieri M. Trends in black and white opioid mortality in the United States, 1979-2015. Epidemiology 2018;29:707-15.

5 Jalal H, Buchanich JM, Roberts MS, et al. Changing dynamics of the drug overdose epidemic in the United States from 1979 through 2016. Science 2018;361:eaau1184.

6 Scholl L, Seth P, Kariisa M, et al. Drug and opioid-involved overdose deaths - United States, 2013-2017. Morbidity and Mortality Weekly Report 2019;67:1419-27.

7 Ruhm CJ. Geographic variation in opioid and heroin involved drug poisoning mortality rates. Am J Prev Med 2017;53:745-53.

8 Rossen LM, Khan D, Warner M. Trends and geographic patterns in Drug-Poisoning death rates in the U.S., 1999-2009. Am J Prev Med 2013:45:e19-25.

9 Rossen LM, Khan D, Warner M. Hot spots in mortality from drug poisoning in the United States, 2007-2009. Health Place 2014;26:14-20.

10 Monnat SM. Factors associated with county-level differences in U.S. drug-related mortality rates. Am J Prev Med 2018;54:611-9.

11 Stewart K, Cao Y, Hsu MH, et al. Geospatial analysis of drug poisoning deaths involving heroin in the USA, 2000-2014. J Urban Health 2017;94:572-86. 
12 Haffajee RL, Lin LA, Bohnert ASB, et al. Characteristics of US counties with high opioid overdose mortality and low capacity to deliver medications for opioid use disorder. JAMA Netw Open 2019;2:e196373.

13 Balmert LC, Buchanich JM, Pringle JL, et al. Patterns and trends in accidental poisoning deaths: Pennsylvania's experience 1979-2014. PLoS One 2016:11:e0151655.

14 Hollingsworth A, Ruhm CJ, Simon K. Macroeconomic conditions and opioid abuse. J Health Econ 2017:56:222-33.

15 Caputi TL, Sabet KA, et al. Population-level analyses cannot tell us anything about individual-level marijuana-opioid substitution. Am J Public Health 2018;108:e12-13.

16 Phelan JC, Link BG, Tehranifar P. Social conditions as fundamental causes of health inequalities: theory, evidence, and policy implications. J Health Soc Behav 2010:51:528-40.

17 Hser Y-I, Evans E, Grella C, et al. Long-Term course of opioid addiction. Harv Rev Psychiatry 2015:23:76-89.

18 Hser Y-I, Hoffman V, Grella CE, et al. A 33-year follow-up of narcotics addicts. Arch Gen Psychiatry 2001:58:503-8.

19 Chatterjee A, Larochelle MR, Xuan Z, et al. Non-Fatal opioid-related overdoses among adolescents in Massachusetts 2012-2014. Drug Alcohol Depend 2019;194:28-31.

20 MacDougall L, Smolina K, Otterstatter M, et al. Development and characteristics of the provincial overdose cohort in British Columbia, Canada. PLoS One 2019:14:e0210129.

21 Campbell $\mathrm{Cl}$, Bahorik AL, VanVeldhuisen $\mathrm{P}$, et al. Use of a prescription opioid registry to examine opioid misuse and overdose in an integrated health system. Prev Med 2018;110:31-7

22 Dasgupta N, Funk MJ, Brownstein JS. Comparing unintentional opioid poisoning mortality in metropolitan and non-metropolitan counties, United States, 1999-2003. In: Thomas YF, Richardson D, Cheung I, eds. Geography and drug addiction. Springer Netherlands: Dordrecht, 2008: 175-92.

23 Keyes KM, Cerdá M, Brady JE, et al. Understanding the rural-urban differences in nonmedical prescription opioid use and abuse in the United States. Am J Public Health 2014;104:e52-9.

24 Wright ER, Kooreman HE, Greene MS, et al. The iatrogenic epidemic of prescription drug abuse: County-level determinants of opioid availability and abuse. Drug Alcohol Depend 2014:138:209-15

25 Dwyer-Lindgren L, Bertozzi-Villa A, Stubbs RW, et al. Trends and patterns of geographic variation in mortality from substance use disorders and intentional injuries among US counties, 1980-2014. JAMA 2018;319:1013-23.

26 Rigg KK, Monnat SM, Chavez MN. Opioid-related mortality in rural America: geographic heterogeneity and intervention strategies. International Journal of Drug Policy 2018:57:119-29.
27 King NB, Fraser V, Boikos C, et al. Determinants of increased Opioid-Related mortality in the United States and Canada, 1990-2013: a systematic review. Am J Public Health 2014;104:e32-42.

28 Gomes T, Juurlink D, Moineddin R, et al. Geographical variation in opioid prescribing and opioid-related mortality in Ontario. Hcq 2011;14:22-4.

29 Cerdá M, Gaidus A, Keyes KM, et al. Prescription opioid poisoning across urban and rural areas: identifying vulnerable groups and geographic areas. Addiction 2017:112:103-12.

30 US Census Bureau. 2013-2017 American community survey (ACS) 5-year estimates. Available: https://www.census.gov/programs-surveys/acs/technicaldocumentation/table-and-geography-changes/2017/5-year.html [Accessed 31 May 2019].

31 Centers for Disease Control and Prevention, National Center for Health Statistics. Compressed mortality file 1999-2016 on CDC wonder online database, 2016. Available: https://wonder.cdc.gov/cmf-icd10.html [Accessed 28 May 2019].

32 Raudenbush SW, Bryk AS. Hierarchical linear models: applications and data analysismethods. 2nd ed. Newbury Park, CA: SAGE, 2002.

33 Larochelle MR, Bernson D, Land T, et al. Medication for opioid use disorder after nonfatal opioid overdose and association with mortality. Ann Intern Med 2018;169:137-45

34 Kim B, Nolan S, Ti L. Addressing the prescription opioid crisis: potential for hospitalbased interventions? Drug Alcohol Rev 2017;36:149-52.

35 Ray BR, Lowder EM, Kivisto AJ, et al. Ems naloxone administration as non-fatal opioid overdose surveillance: 6-year outcomes in Marion County, Indiana. Addiction 2018;113:2271-9.

36 A drugmaker tries to cash in on the opioid epidemic, one state law at a time. al things considered, 2017. Available: https://www.npr.org/sections/health-shots/2017/ 06/12/523774660/a-drugmaker-tries-to-cash-in-on-the-opioid-epidemic-one-statelaw-at-a-time [Accessed 8 May 2019].

37 Lee JD, Nunes EV, Novo P, et al. Comparative effectiveness of extended-release naltrexone versus buprenorphine-naloxone for opioid relapse prevention (X:BOT): a multicentre, open-label, randomised controlled trial. The Lancet 2018;391:309-18.

38 Plebani JG, Oslin DW, Lynch KG. Examining naltrexone and alcohol effects in a minority population: results from an initial human laboratory study. The American Journal on Addictions 2011:20:330-6.

39 Ray LA, Oslin DW. Naltrexone for the treatment of alcohol dependence among African Americans: results from the combine study. Drug Alcohol Depend 2009; 105:256-8.

40 Mattick RP, Breen C, Kimber J, et al. Buprenorphine maintenance versus placebo or methadone maintenance for opioid dependence. Cochrane Database of Systematic Reviews. 